José Guilherme Oliveira ${ }^{1}$

Matheus Tibério ${ }^{2}$

Sarah Venturim Lasso ${ }^{3}$

Sabrina Zanotti Galon ${ }^{4}$

Bruno Felix von Borell Araujo ${ }^{5}$

\title{
COMO OS CASAIS EMPREENDEDORES CAPIXABAS INTERAGEM COM AS FRONTEIRAS ENTRE TRABALHO E LAR?
}

\section{Resumo}

No gerenciamento da vida pessoal e profissional ocorrem conflitos. Principalmente quando se trata de casais que trabalham na mesma empresa. Dessa forma, o objetivo foi identificar as táticas de manejo de fronteiras dos casais empreendedores capixabas que trabalham juntos. A metodologia utilizada foi qualitativa descritiva, através de entrevistas com 6 casais. O resultado mostrou que os casais capixabas conseguem administrar o conflito trabalho-lar. Foram identificadas sete principais táticas de gerenciamento de fronteiras.

Palavras chave: Empreendedorismo, Casais, Conflito trabalho-lar

\section{Abstract}

In the management of the personal and professional life, some conflicts may occur. Mainly when it is about couples who work in the same company. The objective of this paper was identify the main boundary tactics used by the entrepreneurs couples of Espirito Santo who work together. The use methodology was the qualitative descriptive, with six couples interviewed. The results shown that the capixabas entrepreneurs couples are dealing well with the work-home conflict. Seven boundary tactics were identified.

\footnotetext{
Graduando em Administração de Empresas pela Fucape Business School. (jguilhermebaiao@gmail.com)

2 Graduando em Administração de Empresas pela Fucape Business School. (matheustiberio09@hotmail.com)

3 Mestre em Administração pela Fucape Business School. (sarahvlasso@gmail.com)

4 Mestre em Administração pela Fucape Business School. (sabrinazgalon@gmail.com)

5 Doutor em Administração pela UPM e Professor do Programa de Mestrado em Administração da Fucape Business School. (bfelix@fucape.br)
} 


\section{Introdução}

Na tentativa de gerenciar a vida pessoal e profissional, alguns profissionais delimitam fronteiras simbólicas entre os domínios do trabalho e do lar de modo a equilibrar as demandas provenientes destes. Tais fronteiras podem existir de diferentes maneiras. Elas podem ser físicas, temporais, cognitivas e em certos casos a fronteira é estabelecida por um perímetro (SUNDARAMURTHY E KREINER 2008).

Cabe ressaltar que o equilíbrio entre trabalho e família tem um significado diferente para cada indivíduo. É possível que uma mesma família contemple pessoas que possuem pensamentos diferentes em relação ao balanço ideal entre a atmosfera profissional e pessoal, o que torna o equilíbrio entre esses domínios um objetivo a ser atingido por muitas pessoas que fazem parte de um mesmo cenário familiar. Sendo assim, a combinação entre atividades familiares e profissionais para uma pessoa e a quantidade de energia empregada em cada esfera pode não ser a combinação que outra pessoa considere balanceada (CLARK, 2002).

Diante deste contexto, busca-se uma resposta para a seguinte questão: Como os casais empreendedores capixabas interagem com as fronteiras entre trabalho e lar? A fim de responder essa questão, recorrente no cotidiano das pessoas, tem-se como objetivo de pesquisa, identificar as possíveis táticas de manejo de fronteiras utilizadas para equalizar vida pessoal e profissional.

Partindo do pressuposto de que a vida profissional e pessoa tornam-se cada vez mais entrelaçadas, é relevante que esse assunto continue sendo alvo de pesquisas tendo em vista à variedade de preferências individuais em manejar as fronteiras ao seu redor. Apesar de diferentes variações deste tema já terem sido estudadas (KREINER , 2009:, STROBINO E TEIXEIRA, 2014: ROTHBARD ET AL, 2005: INSTRAND ET AL, 2009: GEURTS E TARIS, 2006: DEMOROUTI E GEURTS, 2004: CLARK, 2002: ARAUJO ET AL, 2012), ainda não foi encontrado um estudo relacionado especificamente ao conflito trabalho-lar com casais empreendedores capixabas que atuam no mesmo negócio.

Este trabalho será estruturado da seguinte forma: referencial teórico abordando a Teoria das Fronteiras, as Táticas de Manejo de Fronteiras e o Equilíbrio Trabalho-Lar em casais empreendedores que atuam no mesmo negócio. Em seguida será descrita a metodologia que aborda o método de pesquisa utilizado, a população e amostra e as técnicas de coleta e análise de dados. A concluir tem-se a discussão dos dados e a conclusão do estudo.

\section{Referencial Teórico \\ Táticas de Manejo de Fronteiras}

A literatura contempla alguns estudos sobre conflito trabalho-lar que remetem as táticas de manejo de fronteiras. Kreiner, (2009) aborda os "problemas de fronteira", ou seja, problemas quando um indivíduo da família acaba levando seu trabalho para dentro de casa em uma escala considerada elevada (situação que é ocorre frequentemente nas famílias e principalmente em famílias empreendedoras). Ainda no mesmo estudo, o autor aborda aspectos como a congruência e a incongruência associadas a tais fronteiras. São denominados problemas de incongruência as situações em que um ente familiar não respeita os limites impostos por eles mesmos, acarretando em diversas consequências.

Segundo Kreiner, (2009) as táticas de negociação e fronteiras podem ser classificadas em diferentes tipos, como por exemplo, táticas comportamentais, temporais, físicas e comunicativas, que foram exemplificadas e exploradas a fundo no estudo que Nobrega fez com executivos expatriados (2013).

De acordo com Nóbrega (2013), as táticas comportamentais englobam a tecnologia, que pode ser utilizada não só para agregar a vida profissional ao cotidiano doméstico, mas também 
para segmentar as duas atmosferas. Já em relação às táticas temporais, é possível afirmar que o uso delas permite que o profissional gerencie seu tempo da forma mais conveniente, tendo em vista que nos tempos atuais o "tempo" é um recurso cada vez mais escasso.

Ainda segundo Nóbrega (2013), a forma de manipulação de alguns artefatos físicos, como objetos pessoais e objetos do trabalho, podem representar o uso de táticas físicas, com intuito ou de integrar ou de separar as demandas. Para concluir, as táticas comunicativas são aquelas em que o profissional busca uma comunicação voluntária com outra pessoa, a fim de debater a situação e encontrar uma solução para balancear a questão trabalho-lar.

O estudo de Edrelin (2012), feito com mulheres empreendedoras das Filipinas, concluiu que elas utilizam três táticas para integrar a vida pessoal e o trabalho, que são manter o negócio em casa ou perto de casa, planejar tarefas domésticas com antecedência e praticar atividades que controlem o stress, como yoga, massagens e idas ao shopping.

Os resultados de Araujo et al (2012) sugerem que mulheres brasileiras expatriadas utilizam as táticas de manejo de fronteiras propostas por Kreiner (2009). Segundo o autor, algumas táticas são utilizadas mais que outras e vão de acordo com a rotina de cada pessoa. As pessoas que não dispõem de muito tempo livre estão mais sujeitas ao uso de táticas comportamentais como o uso de outras pessoas.

Táticas temporais são utilizadas como uma forma de fronteira entre os domínios, tanto de trabalho, quanto familiar. O uso das táticas temporais permite que o profissional organize um determinado período de tempo para que nele um domínio não invada o outro, enquanto que as táticas físicas tornam esse período de tempo mais prolongado. (ARAUJO ET AL, 2012),

\section{Conflito Trabalho- Lar}

A questão do equilíbrio trabalho-lar tem emergido como um assunto de muita importância no que se diz respeito a qualidade de vida. As grandes empresas têm se preocupado cada vez mais em permitir que seus colaboradores dediquem certo tempo a sua família. Medidas em prol da família, por parte de algumas empresas tendem a aumentar o nível de retenção de empregados e principalmente a reduzir o nível de stress no local de trabalho. (MOORE 2006)

O resultado de Clark (2002) sugere que quanto mais um profissional se empenha para compartilhar com a família os desafios e o cotidiano vivenciado na empresa, as chances de conflito trabalho-lar são minimizadas e cria-se uma sinergia mais elevada entre as duas esferas (vida social e trabalho).

Ainda de acordo com Moore (2006), homeworkers tem uma flexibilidade e uma independência muito maior do que as de profissionais que trabalhamemescritórios empresariais. Apesar disso, Moore destaca que homeworkers têm mais dificuldades em segmentar a vida profissional e a vida pessoal e estão sujeitos a um nível de stress praticamente igual a de um profissional de escritório. Com isso, percebe-se que mesmo trabalhando em home-office os profissionais estão sujeitos a eventuais conflitos trabalho-lar.

Além da contribuição em relação a táticas de manejo de fronteiras, a obra de Edrelin (2012) também dá destaque aos pontos positivos e negativos da invasão de demandas do trabalho no ambiente pessoal e familiar de algumas mulheres empreendedoras das Filipinas.

Os pontos positivos mais relevantes foram a boa reputação na comunidade, um laço afetivo mais forte entre os familiares, uma renda adequada as necessidades e desejos da família e o aumento do nível do padrão de vida, como por exemplo, a possibilidade de ter uma casa própria, carro de luxo e viagens internacionais (EDRELIN 2012)

Já os pontos negativos mais citados foram a presença de problemas de saúde relacionados ao stress e a exaustão física, a discussão de problemas do negócio durante o tempo de lazer 
com filhos e cônjuge, ter menos tempo para aproveitar junto com os filhos e a abdicação de uma vida social. (EDRELIN 2012)

Em relação a ascensão da mulher no mercado de trabalho, é possível traçar duas linhas de raciocínio. Tendo como base as explicações mais plausíveis para esse rápido crescimento no índice de mulheres em cargos altos administrativos, posteriormente compartilhados com seus maridos sob uma perspectiva igualitária de responsabilidade. Seria uma das teorias focada na carreira em si e nos objetivos almejados. A outra teoria propõe um foco maior na orientação familiar, especialmente perante a presença de filhos (DEMARTINO ET AL, 2006).

Geralmente os rumos da vida profissional e vida pessoal da mulher entram em conflito, o que as força a terem um maior empenho em busca do equilíbrio entra ambas as obrigações. Resultado disso é o frequente conflito entre trabalho-lar, cada vez mais comum na vida destas (MATHEW E PANCHANATHAM, 2011).

A divisão de tarefas vem se tornando algo cada vez mais complicado de se organizar, a discussão sobre "quem vai fazer o quê" em casa acaba sendo um dos principais pontos que permite que o casal continue em harmonia (STANFIELD, 1998)

Além disso, pesquisas como a de Gamor et al (2014) comprovaram que até colaboradores de hotéis que não são casados encontram problemas para balancear atividades familiares e de lazer com a vida profissional, que nesse caso exige presença em datas comemorativas como feriados e também em horários inoportunos. Dessa forma, é possível constatar que não só profissionais casados e com filhos encontram dificuldade para equilibrar trabalho e lazer, mas até pessoas que não tem cônjuge estão sujeitas a enfrentar problemas no que se refere ao equilíbrio trabalho-lar e trabalho-vida social. (GAMOR ET AL, 2014).

Ainda sobre profissões que demandam a presença do profissional em horários que não sejam o comercial, é possível afirmar, segundo a obra de Yldirim e Aycan, (2007) que o excesso de horas de uma jornada de trabalho e escalas de trabalho muito irregulares são precedentes significativos para que haja um conflito trabalho-lar. As autoras ainda sugerem que o bem estar das profissionais em questão, (enfermeiras da Turquia) poderia ser mais elevado caso a jornada de trabalho fosse menor e as escalas menos irregulares.

\section{Casais Empreendedores}

Estudos recentes, como os de Ferguson et al. (2012), sobre casais empreendedores apontam a união e apoio como fatores fundamentais em prol da satisfação e saúde da relação (FERGUSON ET AL., 2012). A natureza conjunta pode apresentar decisões difíceis para vida profissional dos conjugues, seja para escolher um novo lugar para morar ou novas programações na rotina.

Assim, com o passar do tempo é natural que a carreira e interesses únicos de algum dos membros da relação sejam priorizados, visando um bem maior para ambos (DOMENE ET AL., 2012). Dessa forma, é possível determinar dois caminhos para uma percepção fiel ao futuro da organização de mercado. Enquanto em uma das visões o equilíbrio da vida profissional é de fundamental importância na relação entre funcionários e empregadores, no segundo ponto de vista o cultivo da boa relação é restrito aos cargos mais importantes da organização, sem a preocupação social com o elenco da empresa em geral (KALLHASH E KRUSE, 2012).

É natural que os novos casais enfrentem os desafios do mercado de maneira diferente, principalmente baseadas nas experiências pessoais tanto do homem quanto da mulher, de forma a estudá-los como um todo, resultado de recursos humanos unidos pela mesma causa (DOMENE ETAL., 2012). Outro detalhe importante chama a atenção dos pesquisadores, como no estudo de Powell e Eddleston (2013), em que a participação das mulheres no manejo entre 
os ambiente profissional e familiar é de fundamental importância, deixando evidente a maior facilidade e competência das mesmas ao realizar tal equilíbrio, muitas vezes emocionalmente mais efetivo (POWELL E EDDLESTON, 2013).

Considerando a liderança inquestionável necessária no ambiente de trabalho, é de se esperar que a imagem passada pelos empreendedores não é exatamente a encontrada no ambiente familiar. Dessa forma, o departamento de recursos humanos tem um trabalho importante na incorporação da liderança nos cargos de maior reconhecimento, a fim de manter a estabilidade emocional dos associados tanto no trabalho quanto também no contexto familiar (VALK E SRINIVASAN, 2011).

Muito coerente, por sinal, a análise de Moore (2006), referente a alternativa escolhida pelos casais de trabalho em casa, ou "Homeworkers". Tal preferência é de grande valia quando em um cenário onde os filhos são prioridade ou o deslocamento é um obstáculo representativo no cotidiano. Porém, ao contrário do que se esperava, o estresse presente nesses trabalhadores pode ser muitas vezes maior ou igual ao de um trabalhador tradicional, em seu escritório ou empresa. Principalmente no caso das mulheres, que tendem a assumir mais os cuidados com os filhos mais novos, o desgaste tanto físico como emocional, pode fazer dessa alternativa uma extensão dos problemas teoricamente evitados (MOORE, 2006).

\section{Metodologia}

O método utilizado para responder o objetivo deste trabalho é o qualitativo descritivo, caracterizado por não priorizar elementos estatísticos, mas que busca compreender, de certa forma, os diferentes aspectos de cunho comportamental e psicológico e classificar os dados coletados de acordo com características encontradas (EISENHARDT E GRAEBNER, 2007).

Para o projeto em questão, casais capixabas e empreendedores que atuam na mesma empresa foram designados para ser a população. Já a amostra da pesquisa é composta por cinco casais que atendem as características desejadas, escolhidos de forma aleatória.

A coleta dos dados foi efetuada através de entrevistas individuais em profundidade com base em um roteiro semi-estruturado, adaptado a partir de questões usadas por Kreiner et al. (2009). Nas entrevistas, os casais foram entrevistados separadamente, com duração média de 30 minutos. O roteiro das entrevistas contemplava 14 perguntas divididas em 6 seções, tais como: Perfil do entrevistado; Desafios e táticas relacionados ao equilíbrio trabalho-lar; Preferências individuais por segmentação ou integração; Preferências da empresa e da família por segmentação ou integração; Táticas utilizadas e Experiências adicionais. Todas as entrevistas foram transcritas e seguiram os princípios da amostragem teórica (GLASER, 1998).

$\mathrm{Na}$ fase da análise dos dados utilizou-se a análise de conteúdo (BARDIN, 2004; KRIPPENDORFF, 1980) a fim de identificar as possíveis táticas de manejo de fronteiras utilizadas para equalizar vida pessoal e profissional.

\section{Análise dos Dados}

Após revisar a literatura acerca do tema e também levando em conta o objetivo de identificar as táticas vivenciadas por casais empreendedores capixabas atuantes em uma mesma empresa, a análise das entrevistas dos casais sugere que na maioria das vezes as táticas de manejo de fronteiras são utilizadas (KREINER et al. 2009), ainda que involuntariamente. Já em relação aos problemas vivenciados, nas entrevistas os casais não revelaram lidar com grandes adversidades.

O quadro 1 abaixo representa as características dos empreendedores que participaram do estudo. 
Quadro 1: Perfil dos participantes da pesquisa

\begin{tabular}{|c|c|c|c|c|c|c|}
\hline Indivíduo & Tdade & $\begin{array}{l}\text { Cargo na em- } \\
\text { presa }\end{array}$ & $\begin{array}{ll}\text { Área } & \text { da } \\
\text { Empresa }\end{array}$ & Filhos & Escolaridade & $\begin{array}{l}\text { Tamanho } \\
\text { da em- }\end{array}$ \\
\hline $\mathrm{C} 1 \mathrm{M}$ & 64 & $\begin{array}{ll}\text { Gerência } & \mathrm{e} \\
\text { Proprietária } & \end{array}$ & Restaurante & 2 & $\begin{array}{l}\text { Ensino Mé- } \\
\text { dio Comple- }\end{array}$ & presa \\
\hline $\mathrm{ClH}$ & 50 & $\begin{array}{l}\text { Chefe de Cozi- } \\
\text { nha e Proprie- } \\
\text { tário. }\end{array}$ & Restaurante & 0 & $\begin{array}{l}\text { Ensino Fun- } \\
\text { damental In- } \\
\text { completo }\end{array}$ & Micro \\
\hline $\mathrm{C} 2 \mathrm{M}$ & 54 & $\begin{array}{l}\text { tario } \\
\text { Proprietária }\end{array}$ & Comércio & 1 & $\begin{array}{l}\text { completo } \\
\text { Ensino Mé- } \\
\text { dio Comple- } \\
\text { to }\end{array}$ & Micro \\
\hline $\mathrm{C} 2 \mathrm{H}$ & 63 & Proprietário & Comércio & 1 & $\begin{array}{l}\text { Ensino Mé- } \\
\text { dio Comple- } \\
\text { to }\end{array}$ & Micro \\
\hline C3 M & 44 & $\begin{array}{ll}\text { Advogado } & \text { e } \\
\text { Pronrietário } & \end{array}$ & Advocacia & 1 & Pós Gradua- & Micro \\
\hline $\mathrm{C} 3 \mathrm{H}$ & 45 & $\begin{array}{l}\text { Advogado } \\
\text { Proprietário }\end{array}$ & Advocacia & 1 & $\begin{array}{l}\text { Pós Gradua- } \\
\text { do }\end{array}$ & Micro \\
\hline C4 M & 58 & $\begin{array}{l}\text { Diretora Peda- } \\
\text { gógica }\end{array}$ & $\begin{array}{l}\text { Escola de } \\
\text { Idiomas }\end{array}$ & 2 & $\begin{array}{l}\text { Pós Gradua- } \\
\text { da }\end{array}$ & Micro \\
\hline $\mathrm{C} 4 \mathrm{H}$ & 61 & $\begin{array}{l}\text { Diretor Admi- } \\
\text { nistrativo }\end{array}$ & $\begin{array}{l}\text { Escola de } \\
\text { Idiomas }\end{array}$ & 2 & Graduado & Micro \\
\hline C5 M & 44 & $\begin{array}{l}\text { Coordenadora } \\
\text { Pedagógica }\end{array}$ & $\begin{array}{l}\text { Escola de } \\
\text { Idiomas }\end{array}$ & 1 & Graduada & Micro \\
\hline $\mathrm{C} 5 \mathrm{H}$ & 42 & $\begin{array}{l}\text { Gestor Admi- } \\
\text { nistrativo }\end{array}$ & $\begin{array}{l}\text { Escola de } \\
\text { Idiomas }\end{array}$ & 1 & Graduado & Micro \\
\hline C6 M & 46 & Proprietaria & $\begin{array}{l}\text { Hotel para } \\
\text { cães }\end{array}$ & 0 & Mestranda & Micro \\
\hline C6 H & 49 & Proprietário & $\begin{array}{l}\text { Hotel para } \\
\text { cães }\end{array}$ & 2 & $\begin{array}{l}\text { Ensino Mé- } \\
\text { dio Comple- } \\
\text { to }\end{array}$ & Micro \\
\hline
\end{tabular}

Fonte: dados da pesquisa.

A partir da análise dos dados coletados, foi possível perceber a utilização de diferentes táticas de negociação de fronteiras (KREINER et al. 2009) por parte dos indivíduos entrevistados. Nos tópicos a seguir estarão descritas tais táticas encontradas no estudo, bem como suas descrições junto à fala dos sujeitos.

\section{Separando demandas profissionais e pessoais}

Essa tática refere-se em estabelecer algumas fronteiras para a execução de atividades de diferentes domínios. Tal comportamento permite ao profissional segmentar as demandas da esfera do trabalho e da vida social. Os trechos a seguir evidenciam essa questão:

"Aqui dentro nós nos tratamos como ela coordenadora e eu como diretor, nada de marido e esposa. Raramente trato de meus assuntos pessoais quando estou aqui dentro." (C5H) "A gente não costuma levar nada de casa pro trabalho. Aqui o trabalho para nós é praticamente uma terapia. Ele $(\mathrm{C} 1 \mathrm{H})$ faz tudo com muito amor e muito carinho e a gente procura no nosso ambiente de trabalho ser um ambiente alegre. Então, conclusão: não levamos nenhum problema de casa para o restaurante. A gente aqui trabalha assim... Pra separar bem as coisas e não misturar as coisas. Quando estamos aqui no trabalho, a gente vive o trabalho $(\ldots) "(\mathrm{C} 1 \mathrm{M})$ 
"(...) Eu não costumo misturar. Meu trabalho é meu trabalho. Momento de eu curtir é momento de eu curtir. (...) Mudou com o tempo. A gente consegue enxergar que não é certo levar as coisas do trabalho para casa, porque se não você não consegue descansar." $(\mathrm{C} 1 \mathrm{H})$

Conforme as falas descritas, percebe-se que esses indivíduos se habituaram a não tratar de assuntos pessoais durante o período de trabalho no restaurante. Além disso, foi possível perceber também que o mesmo casal adota uma postura semelhante em relação a não levar demandas profissionais para o lar.

Outros entrevistados também deram depoimentos relatando a preferência por manter os dois domínios (trabalho-lar) separados (trabalho e outras atividades sociais), conforme descrito a seguir:

“(...) Procuramos manter a vida pessoal distante, em muitos casos, da vida profissional, para que possamos nos desconectar e aproveitar o lazer em família." (C3H)

A criação de uma fronteira entre a esfera profissional e pessoal permite que o profissional viva cada momento com uma dedicação quase que exclusiva. É importante ressaltar que a criação desse tipo de fronteira não é necessariamente a melhor forma de balancear trabalho e família para todos os casais, mas sim uma alternativa a ser utilizada por alguns perfis de pessoas.

Vale a pena lembrar que outros indivíduos entrevistados se mostraram complacentes quanto a não levar trabalho para casa. Entretanto, esses mesmos indivíduos se se sentem mais confortáveis em resolver demandas pessoais no período e no local de trabalho, como comprovado pela fala do entrevistado abaixo.

"Eu resolvo meus problemas pessoais dentro da empresa. São vários, até a manutenção da casa. E outras atividades que eu tenho, então eu resolvo até pelo tempo que eu tenho disponível e que posso fazer isso. (...) Quando encaixa, eu resolvo. Vou lá matar cupim lá em casa. Por que eu estou 24h aqui. Daqui eu não consigo resolver não." (C4H)

\section{Selecionando demandas a serem executadas}

Apesar de a maioria dos empreendedores participantes do estudo ter como característica a preferência pela segmentação das demandas, foi possível constatar também que alguns deles filtravam as atividades mais relevantes do dia a dia a serem executados em ambos os domínios de modo a não prejudicar o desempenho desejável das demandas relacionadas a estes.

"Eu geralmente a única coisa que levo é que quando chego em casa eu ponho tudo no computador, vou fazer serviços de banco e faço todas essas coisas assim. Fora disso, ou a gente conversa sobre algum problema que houve no restaurante, mas pouca coisa." $(\mathrm{C} 1 \mathrm{M})$

"(...) O horário que estamos no trabalho é o horário que tudo acontece, horário comercial. É o tempo que temos de pagar alguma conta, ligar para minha família que é de Manaus." (C3M)

Essa estratégia revela que por mais que exista a preferência pela segmentação, determinadas tarefas do trabalho acabam tendo que ser executadas em casa e vice versa, rompendo a fronteira entre trabalho-lar, assim como apresenta o estudo realizado por Nóbrega (2013), desde que tais atividades não comprometam o equilíbrio desejável relacionado aos domínios. 
Foi possível constatar também, que os entrevistados relataram ter flexibilidade para poder resolver alguma demanda pessoal no ambiente de trabalho, o que já era de certa forma esperado, tendo em vista que eles são os próprios chefes. Tal constatação pode ser vista a seguir:

"(...) Não existe tanta cobrança assim nesse caso, há espaço para o lado pessoal no trabalho, desde que não comprometa as metas." (C3H)

\section{Adquirindo experiência}

De acordo com os empresários que cooperaram com o projeto, atingir um bom equilíbrio entre atividades profissionais e vida pessoal requer certo tempo de amadurecimento tanto como profissional, quanto como casal. Essa tática, que envolve conhecer bem a pessoa com quem está lidando, está atrelada ao mútuo conhecimento por parte de cada casal. Eles reportaram que o começo do negócio sempre foi um período crítico no que se diz respeito a equilíbrio trabalho-lar. Nessa fase do negócio, a integração das demandas era mais recorrente.

"No começo você mistura. Aos pouquinhos você vai conseguindo separar. Fazem 15 anos que a gente tem a escola. A gente já conseguiu chegar em um nível de estabilidade, tanto de emocional, quanto de tudo (...)" (C3M)

“(...) Nós somos um pouco mais experientes, pois lá em São Paulo a gente já teve dois restaurantes. Esse é o terceiro, então a gente já sabe mais ou menos como anda (...). (C1M)

Aparentemente, quanto mais tempo de convívio tem um casal empreendedor, o alcance do equilíbrio entre o trabalho e lazer fica mais próximo, devido justamente ao estágio avançado de compreensão e consequentemente amadurecimento profissional por causa do decorrer do tempo.

"(...) a maturidade adquirida ao longo do tempo com o convívio facilita a cooperação, o trabalho." (C3H)

\section{Dialogando com os envolvidos}

O uso dessa tática refere-se a estabelecer um diálogo entre as pessoas envolvidas em relação às demandas da vida familiar e profissional. O método em questão aposta na comunicação como uma ferramenta que mitigue a questão do conflito trabalho-lar.

"É difícil, mas é tudo com conversa mesmo porque não existe outra solução se não for conversa. A comunicação é fundamental muito diálogo entre eu e ela, no caso (...)" (C1H)

"Acredito que isso é uma questão que tem que ser bem conversada, antes de iniciar um empreendimento, é necessário que o casal se entenda bem, uma vez que forem de áreas muito diferentes como um médico e uma comerciante, talvez seja melhor focar cada um na sua própria carreira. Tem que ser algo bem conversado." $(\mathrm{C} 2 \mathrm{H})$

O diálogo mostrou-se uma das técnicas mais relevantes e eficientes entre os entrevistados. Assim como proposto por Clark (2002), ficou claro que manter uma constante comunicação entre os membros do casal é importante para o manejo das tarefas e para a redução de conflitos trabalho-lar. Além de Clark (2002), Nóbrega (2013) também citou a comunicação direta, classificando essa tática como sendo uma tática rotineira. 


\section{Integrando as demandas e os domínios}

Apesar de a maioria dos entrevistados revelarem possuir um perfil segmentador em relação ao assunto, houve casais que descreveram a utilização de táticas integradoras, que diminuem a fronteira para a execução das demandas de diferentes domínios.

Sem deixar as obrigações de lado, a integração de tarefas pessoais ao ambiente de trabalho e seus domínios tem se tornado muito presente no cotidiano desses empresários. Considerando a grande demanda de tarefas a serem atendidas, a organização na hora de integrar é essencial.

"(...) Resolvo muitas coisas pessoais enquanto estou no trabalho por estar em família também. " (C2M)

"Acho que o fator principal nesse caso é o de confiança, entre o marido e mulher. 0 negócio não vai pra frente se houverem muitas divergências nesse sentido. O trabalho é assunto aberto dentro de casa." $(\mathrm{C} 2 \mathrm{H})$

Analisando o perfil de alguns empreendedores nos dias de hoje, é natural que encontremos um trabalho com múltiplas funções tanto no âmbito familiar quanto no profissional. Afim de cumprir com todas as suas responsabilidades, o profissional se vê disposto a integrar as demais tarefas ao ambiente de trabalho.

Os entrevistados se mostraram capazes e organizados o suficiente para manter essa relação entre as tarefas integradas e o trabalho. Assim como no estudo de Edralin (2012), a pré-organização se mostrou uma ferramenta de auxílio importante para aqueles que optam por um perfil integrador.

\section{Unindo-se para atender as demandas}

A fim de manter uma harmonia, tanto no ambiente de trabalho, quanto na vida pessoal, alguns empreendedores prezam pela união entre as pessoas, principalmente do casal, para atender as demandas provenientes de cada esfera.

Notou-se que esse tipo de tática de negociação de fronteiras é bastante recorrente em empresas familiares.

"Na minha casa todos estão comprometidos com o trabalho e todos estão focados para obter resultado. Cada um veio de um área diferente mas tocamos o negócio juntos. O fator principal é a união." (C2H)

A utilização dos valores familiares como um alicerce no dia a dia empresarial pode significar um ponto positivo para alguns empreendedores. Em algumas situações imprevistas, ter o parceiro e outros membros da família envolvidos no negócio pode até se transformar em uma vantagem competitiva, ou pelo menos um alívio, conforme o relato a seguir:

“(...) Eu saí da escola. A escola funcionou do mesmo jeito. Todo mundo cobriu tudo quando é horário e a escola inteira participou dos 30 dias de coma do meu marido. Eu saia e entrava em horários fora do comum. (...) Não tem como explicar como a gente funcionou. Motorista faxinou. Todo mundo fez tudo. Foram 30 dias de corrida." (C4M)

\section{Segregando o ambiente de trabalho}

Além das táticas observadas acima, encontrou-se também uma tática que faz com que o casal, por mais que trabalhe na mesma empresa, não esteja em contato direto durante a 
jornada de trabalho. Segundo as entrevistas, para alguns indivíduos a presença do cônjuge vinte e quatro horas por dia pode acabar desgastando a relação, tanto profissional, quanto pessoal.

"Desde o começo eu propus de quando eu estivesse em uma das unidades, que ele ficasse em outra. Não faz sentido ficarem os dois no mesmo lugar e é desgastante. (...) A proposta é enquanto um estiver em uma unidade na Praia do Canto, por exemplo, o outro toma conta da unidade de Jardim Camburi." (C5M)

Vale a pena lembrar que esse tipo de tática pode ser aplicado não só em empresas que possuem filiais, como no caso da entrevistada. Essa segregação do ambiente de trabalho poderia se dar também através da separação do escritório de trabalho, dentro de uma própria unidade, por exemplo.

\section{Discussão}

É natural que os resultados de uma pesquisa de campo na qual se aborda um tema cotidiano surpreendam os pesquisadores e levem a tona alguns pontos antes inesperados ou desconhecidos. Em relação aos casais empreendedores entrevistados, não foi diferente. Durante o projeto, teve-se a oportunidade de entrevistar pessoas com características distintas, tanto nos aspectos pessoais, como origens e valores, quanto em questões relacionadas ao grau de escolaridade e experiência profissional.

Apesar de os indivíduos que compuseram a amostra possuírem características distintas, foi possível notar a necessidade que todos tinham de gerenciar as fronteiras entre trabalho e lar e que, seguindo a análise de Nóbrega (2013) e Kreiner (2009) cada um utiliza táticas diferentes, que a eles convêm, sejam elas comportamentais, temporais, físicas ou comunicativas.

Esperava-se que os casais empreendedores tivessem mais dificuldade em organizar vida profissional e social, pois a presença do cônjuge no ambiente de trabalho e do sócio no ambiente familiar é um potencial fator de distração. Entretanto, diferentemente do que era esperado, concluiu-se que os casais empreendedores capixabas estão conseguindo lidar com tal confronto e minimizar os problemas relacionados ao equilíbrio entre a vida profissional e pessoal através do uso de táticas de manejo. Vale lembrar, que o uso dessas táticas para alguns deles se dá de forma natural, ou seja, não há uma conversa, uma reunião entre o casal sobre táticas de manejo de fronteiras.

É possível dizer também, que o tipo de tática utilizada não apresentou relação com o nível de escolaridade e de renda, tendo em vista que um microempresário proprietário de um pequeno restaurante utiliza o mesmo tipo de tática de manejo (física) que, segundo Nóbrega (2013), utiliza um executivo de uma grande empresa brasileira no exterior.

Além disso, pelo fato dos empreendedores entrevistados possuírem empresas familiares, esperava-se uma maior dificuldade na segmentação das demandas profissionais e pessoais. No entanto, foi constatado que os microempreendedores entrevistados optam, em maioria, por separar assuntos da vida pessoal e do trabalho.

Outro fator importante relatado pelos entrevistados foi o desenvolvimento pessoal ao longo do tempo e a confiança depositada no seu parceiro após um considerável período de convívio. Na perspectiva de alguns casais, é de extrema importância a construção de um relacionamento sólido, para que, uma vez no mercado de trabalho, os eventuais problemas particulares interfiram o mínimo possível no dia a dia da empresa.

Em suma, percebeu-se que poucos casais encaram o equilíbrio trabalho-lar como um problema sem solução. Todos afirmaram que é possível manter as duas esferas em harmonia, mesmo que para isso seja necessária uma maior organização por parte do casal. Tal necessidade de organização já fora sugerida por um estudo de Edralin, realizado no ano de 2012. 


\section{CONCLUSÃO}

Considerando o atual cenário da literatura de fronteiras entre trabalho e lar, foi identificada uma lacuna ao que se refere aos conflitos entre casais empreendedores capixabas que trabalham juntos em um mesmo negócio. Após analisar várias táticas de manejo, planejamentos, rotinas diferenciadas de trabalho e diversos modos de integração, foi possível atingir o objetivo de identificar características e conflitos de uma relação entre trabalho e lar de forma geral. A coleta de dados para embasamento foi feita a partir de entrevistas e contato direto com os casais empreendedores, sendo uma série de perguntas feitas para cada um dos conjugues individualmente, a fim de obter as respostas mais fiéis possíveis e evitar que a pesquisa fosse enviesada.

Dessa forma, foi possível identificar as táticas e ferramentas que os indivíduos utilizam para balancear a vida profissional e pessoal. Além disso, foi possível também traçar um perfil de alguns problemas que os casais de hoje em dia enfrentam, dado o tipo de mercado e modo como é imposto o estilo de vida padrão de um empreendedor.

Pode-se dizer que o resultado no geral foi compatível com o esperado. A surpresa maior foi em relação à segmentação dos assuntos de trabalho no ambiente familiar, esse tipo de tática mostrou-se mais comum e evidente do que o esperado antes do início das pesquisas.

Acredita-se que a contribuição mais significativa foi a produção de uma pesquisa com um considerável nível de aprofundamento referente à população em questão

É possível citar algumas limitações do estudo, bem como o tamanho da amostra e a presença absoluta de microempresas administradas pelos casais.

\section{REFERÊNCIAS}

ARAUJO, B. ,ROSA, A. \& TURETA, C. Negociando as Fronteiras entre Trabalho-Lar no Contexto dos Negócios Internacionais: um Estudo com Mulheres Expatriadas, in Enanpad, XXXVI, 2012, Rio de Janeiro. Anais... Rio de Janeiro: Anpad, 20122012

$\begin{array}{ccccccc}\text { CLARK, Sue Campbell. } & \text { Communicating across the } & \text { work/ } \\ \text { home border.Community, Work \& Family, v. 5, n. } 1, \quad \text { p. 23-48, } 2002 .\end{array}$

DEMARTINO, Richard;BARBATO, Robert;JACQUES, PaulH.Exploring thecareer/achievement and personallife orientation differences betweenentrepreneursand nonentrepreneurs: the impact of sex and dependents.Journal of Small Business Management, v. 44, n. 3, p. 350-368, 2006.

DEMEROUTI, Evangelia; GEURTS, Sabine. Towards a typology of workhome interaction. Community, Work \& Family, v. 7, n. 3, p. 285-309, 2004.

EDRALIN, Divina M. Innovative work-life balance strategies of Filipina entrepreneurs: New evidence from survey and case research approaches.Procedia-Social and Behavioral Sciences, v. 57, p. 201-208, 2012.

DOMENE, José F. et al. Young adult couples transitioning to work: The intersection of career and relationship. Journal of Vocational Behavior, v. 81, n. 1, p. 17-25, 2012.

EISENHARDT, Kathleen M.; GRAEBNER, Melissa E. Theory building from cases: opportunities and challenges. Academy of management journal, v. 50, n. 1, p. 25-32, 2007.

FERGUSON, Merideth et al. Support at work and home: The path to satisfaction through balance. Journal of Vocational Behavior, v. 80, n. 2, p. 299-307, 2012. 
GAMOR, Emmanuel; AMISSAH, Eunice Fay; BOAKYE, Kwaku Adutwum Anyim. Work-family conflict among hotel employees in Sekondi-Takoradi Metropolis, Ghana. Tourism Management Perspectives, v. 12, p. 1-8, 2014.

INNSTRAND, Siw Tone et al. Work-home conflict and facilitation across four different family structures in Norway. Community, Work \& Family, v. 13, n. 2, p. 231-249, 2010.

MATHEW, Rincy V.; PANCHANATHAM, N. An exploratory study on the work-life balance of women entrepreneurs in South India. Asian Academy of Management Journal, v. 16, n. 2, p. $77-105,2011$.

MOORE, J. Homeworking and work-life balance: does it add to quality of life?. Revue Européenne de Psychologie Appliquée/European Review of Applied Psychology, v. 56, n. 1, p. 5-13, 2006.

NÓBREGA, Marcos Roberto. Como Executivos Expatriados Negociam As Fronteiras Entre Trabalho E Lar Durante A Designação. 2013. $72 f$. Dissertação (Mestrado em Administração)/Fundação Instituto Capixaba De Pesquisas Em Contabilidade, Economia E Finanças-Fucape, Vitória, 2013.

POWELL, Gary N.; EDDLESTON, Kimberly A. Linking family-to-business enrichment and support to entrepreneurial success: do female and male entrepreneurs experience different outcomes?. Journal of Business Venturing, v. 28, n. 2, p. 261-280, 2013.

ROTHBARD, Nancy P.; PHILLIPS, Katherine W.; DUMAS, Tracy L. Managing multiple roles: Work-family policies and individuals' desires for segmentation. Organization Science, v. 16, n. 3, p. 243-258, 2005.

STANFIELD, Jacqueline B. Couples coping with dual careers: A description of flexible and rigid coping styles. The Social Science Journal, v. 35, n. 1, p. 53-64, 1998.

SUNDARAMURTHY, Chamu; KREINER, Glen E. Governing by managing identity boundaries: The case offamily businesses. Entrepreneurship Theory and Practice, v. 32, n. 3, p. 415-436, 2008.

VALK, Reimara; SRINIVASAN, Vasanthi. Work-family balance of Indian women software professionals: A qualitative study. IIMB Management Review, v. 23, n. 1, p. 39-50, 2011.

VAN HOOFF, Madelon LM et al. Work-home interference: How does it manifest itself from day to day?. Work \& Stress, v. 20, n. 2, p. 145-162, 2006.

YILDIRIM, Dilek; AYCAN, Zeynep. Nurses' work demands and work-family conflict: A questionnaire survey. International journal of nursing studies, v. 45, n. 9, p. 1366-1378, 2008. 